\title{
A liquid phase blocking ELISA for the detection of antibodies against infectious bronchitis virus
}

T.C. Cardoso ${ }^{1}$ R.L. Mouro-Sousa ${ }^{2}$, C. Oliveira ${ }^{3}$, G. Stringhini ${ }^{1}$ and A. Augusto-Pinto ${ }^{2}$
${ }^{1}$ Departamento de Apoio, Produção e Saúde Animal, Faculdade de O dontologia, Universidade Estadual Paulista, Araçatuba, SP, Brasil

${ }^{2}$ Departamento de M icrobiologia, Faculdade de Ciências Agrárias e Veterinárias, Universidade Estadual Paulista, Jaboticabal, SP, Brasil

3M erial Laboratories, Setor de Biologia Aviária, Campinas, SP, Brasil

\section{Correspondence \\ T.C. Cardoso \\ Departamento de Apoio, Produção e Saúde Animal \\ Curso de Medicina Veterinária \\ Rua Clóvis Pestana, 793 \\ 16015-050 Araçatuba, SP \\ Brasil \\ Fax: +55-18-622-6487 \\ E-mail: tcardoso@ fmva.unesp.br}

Reasearch supported by FAPESP (No. 1997/10877-2).

Received June 18, 1998

Accepted February 26, 1999

\section{Abstract}

A liquid phase blocking ELISA (LPB-ELISA) was developed for the detection and measurement of antibodies against infectious bronchitis virus (IBV). The purified and nonpurified virus used as antigen, the capture and detector antibodies, and the chicken hyperimmune sera were prepared and standardized for this purpose. A total of 156 sera

\section{Key words}

- Liquid phase blocking ELISA

- Humoral response

- Infectious bronchitis virus from vaccinated and 100 from specific pathogen-free chickens with no recorded contact with the virus were tested. The respective serum titers obtained in the serum neutralization test (SNT) were compared with those obtained in the LPB-ELISA. There was a high correlation $\left(r^{2}=0.8926\right)$ between the two tests. The LPB-ELISA represents a single test suitable for the rapid detection of antibodies against bronchitis virus in chicken sera, with good sensitivity (88\%), specificity (100\%) and agreement (95.31\%).

Infectious bronchitis virus (IBV) infects the respiratory tract, kidneys and oviduct of chicks of all ages causing retarded growth, mortality, reduced egg production and inferior egg shell quality (1). For the control of virus infection, broilers are vaccinated at one day of age with live attenuated vaccines. Breeders and egg layers are vaccinated at approximately 8-week intervals with live attenuated vaccines and with inactivated vaccines after they start laying eggs (2).

IBVs contain four structural proteins: $\mathrm{S}_{1}$ and $\mathrm{S}_{2}$, with $\mathrm{Mr}$ of $92 \mathrm{~K}$ and $84 \mathrm{~K}$, respectively, as well as the heterogeneously glycosylated membrane polypeptide $\mathrm{p} 23$ with an $\mathrm{Mr}$ of $34 \mathrm{~K}$, and the nucleocapsid protein with an Mr of $52 \mathrm{~K}$ associated with RNA (3).
The role of $S_{1}$ glycoprotein in the induction of humoral antibody responses has been extensively studied, and the protein has been shown to induce both virus neutralization and hemagglutination-inhibiting (HI) antibodies $(1,2)$. Acute infections are generally diagnosed by the immunofluorescence test (IFT) or virus isolation. Serological assays such as the HI test, the agar gel precipitation test, and the enzyme-linked immunosorbent assay (ELISA) are also used for serological IBV monitoring (4). Although the serum neutralization test (SNT) is the only technique that can measure the neutralizing antibodies against IBV, it is rarely used because of its high cost and laborious execution. In broilers, the usually short time between infection 
and slaughter may hamper the interpretation of serological results. A field study on commercial broiler flocks without clinical infection favored the use of an indirect and sandwich ELISA for the serological diagnosis of the IBV humoral response (4-7). Thus, we developed and standardized a liquid phase blocking ELISA (LPB-ELISA), and compared its results with those obtained by the SNT for the detection of neutralizing antibodies against IBV.

\section{Virus antigen}

The Massachusetts strain (Mass 41) of IBV was propagated by infecting 9-11-dayold embryonated specific pathogen-free (SPF) eggs and the allantoic fluid was harvested as recommended (3). The virus was further purified by previously reported methods $(5,6)$ with some modifications. Briefly, the allantoic fluid collected and pooled from IBV-infected SPF embryonated eggs was clarified by centrifugation at 2,000 $\mathrm{g}$ for 20 $\min$ at $4^{\circ} \mathrm{C}$ and then submitted to $59,000 \mathrm{~g}$ for ultracentrifugation. The viral pellet was resuspended in $3 \mathrm{ml}$ of TNE buffer $(1 \mathrm{mM}$ TRIS, $0.15 \mathrm{M} \mathrm{NaCl}, 1 \mathrm{mM}$ EDTA, pH 7.0) and layered on a continuous $20-55 \%$ sucrose gradient (w/v) and centrifuged at 90,000 $\mathrm{g}$ for $10 \mathrm{~h}$ at $4^{\circ} \mathrm{C}$. The fractions collected from the gradient which absorbed at $254 \mathrm{~nm}$ (viral RNA) and $280 \mathrm{~nm}$ (total protein) were pooled and diluted in TNE buffer and the protein concentration was determined by the method of Hartrée (7). The virus infectivity was titrated in SPF embryonated eggs, as recommended (1). The same IBV strain, replicated in embryonated SPF eggs and clarified at low-speed centrifugation, was used as nonpurified antigen in the LPB-ELISA.

\section{Capture antibody}

The chicken IBV-specific $\boldsymbol{\gamma}$-globulin was used as the capture antibody. For this purpose, only one group of SPF white Legorns chicks was used. An inbred $\mathrm{C} / \mathrm{O}$ Line obtained from Merial Laboratories was placed in positive pressure isolation units at one day of age. These ten chicks were vaccinated intra-ocularly (io) with $10^{4.0} \mathrm{CD}_{50}$ of purified M41 strain in $50 \mu 1$ of phosphate-buffered solution (PBS) at 2, 6 and 10 weeks of age, respectively. After these procedures, all chicks were again vaccinated intramuscularly at two weeks of age with $0.5 \mathrm{mg}$ of inactivated purified M41 strain in $100 \mu$ of PBS mixed with Freund's complete adju$\operatorname{vant}(1: 1)$. At 6 and 10 weeks of age these ten chicks were revaccinated intramuscularly with $0.5 \mathrm{mg}$ of inactivated purified M41 strain in $100 \mu 1$ of PBS mixed with Freund's incomplete adjuvant (1:1). The chicks were bled from the wing vein ten days after the last vaccination. The chicken IBV-specific $\gamma$-globulin fraction was obtained as described previously (8). The capture antibody (specific $\gamma$-globulin fraction against purified IBV) was titrated by the SNT.

\section{Detector antibody}

The detector antibody was prepared by the immunization of three guinea pigs with purified IBV as described in previous articles $(6,7)$.

\section{Serum samples}

A total of 156 serum samples collected from different vaccinated commercially bred chickens and 100 serum samples from SPF chickens were titrated both by LPB-ELISA and SNT. A positive reference serum was obtained as described previously (6). The negative reference serum consisted of a mixture of 10 serum samples collected from SPF chickens.

\section{Serum neutralization test}

The reagents and the basic procedures used were described before. Briefly, dilu- 
tions of the chicken sera were mixed with $100 \mathrm{TCID}_{50}$ of the Mass $41 \mathrm{IBV}$ strain in microtiter plates (Nunc, Copenhagen, Denmark) and incubated for $1 \mathrm{~h}$ at $37^{\circ} \mathrm{C}$. Thereafter, an equal volume of chicken embryonated kidney cells at $10^{6}$ cells $/ \mathrm{ml}$ was added to each well and the plates were further incubated at $37^{\circ} \mathrm{C}$. The reduction in virusspecific cytopathic effect was observed after 48 and $72 \mathrm{~h}$ and the virus neutralization titer of the serum calculated by the Spearm-Karber method $(6,7)$.

\section{Development of LPB-ELISA}

Optimal dilutions of all reagents (capture antibody, detector antibody, serum samples and nonpurified virus) were determined using chessboard titration (9). Different capture antibody dilutions were tested against several unpurified viral antigen concentrations in order to detect the best discrimination between the positive and the negative reference sera (10).

\section{Application of LPB-ELISA}

The test was performed as described by McCullough et al. (10) and Araujo et al. (11), with some modifications. The microplate (Nunc) wells were coated with the capture antibody diluted 1:250 or $12.5 \mu \mathrm{g} /$ well overnight, in $0.05 \mathrm{M}$ carbonate bicarbonate buffer, $\mathrm{pH} 9.6$, at $4^{\circ} \mathrm{C}$. After five washings with phosphate-buffered saline solution containing $0.05 \%$ Tween 20 (PBST), the plates were blocked with PBS containing $15 \%$ skim milk (PBSM). After incubation for $45 \mathrm{~min}$ at $37^{\circ} \mathrm{C}$, the plates were ready for use. The sera to be tested, always run in duplicate, were treated with $1 \%$ trichloroacetic acid for protein precipitation before mixing with a fixed concentration of unpurified virus dilution (1:5), also diluted in PBS with $0.5 \mathrm{M} \mathrm{NaCl}$. This liquid phase was executed in separated hemagglutination plates (Nunc) and after incubation at $37^{\circ} \mathrm{C}$ for 90 min the virus-sera mixture was transferred to the ELISA plates and incubated at $37^{\circ} \mathrm{C}$ for $60 \mathrm{~min}$. The IBV antigen (M41 strain) was stored at $-70^{\circ} \mathrm{C}$ and used at a concentration of 1:5, which gave an absorbance of 1.5 at $492 \mathrm{~nm}$, and the plates were washed as before. An optimal 1:4000 dilution of guinea pig detector anti-IBV serum in phosphate-buffered solution containing Tween and skim milk (PBSTM) was added and the plates were incubated for $60 \mathrm{~min}$ at $37^{\circ} \mathrm{C}$. An optimal 1:16,000 dilution of commercial rabbit anti-guinea pig IgG conjugated to horseradish peroxidase (Sigma Chemical Co., St. Louis, MO, USA) in PBSTM was added. After incubation for 60 $\min$ at $37^{\circ} \mathrm{C}$, the plates were again washed as described previously. A mixture of $0.006 \%$ $\mathrm{H}_{2} \mathrm{O}_{2}$ and $0.4 \mathrm{mg}$ o-phenylenediamine $/ \mathrm{ml}$, $0.1 \mathrm{M} \mathrm{Na}_{2} \mathrm{HPO}_{4}$ and $0.1 \mathrm{M}$ citric acid buffer, $\mathrm{pH}$ 5.0, was used as substrate and chromogen. After 15 min of incubation at room temperature, $2 \mathrm{M} \mathrm{HCl}$ was added in order to block the enzymatic reaction, and the OD of the plate was read at $492 \mathrm{~nm}$ in a Titerteck multiscan reader. On each plate, 22 wells were used for antigen control with no test sera added, and 2 wells were used for the reciprocal serum dilution that inhibited color development in relation to the 22 antigen control wells. The following formula was used for this determination:

$$
\mathrm{T}=\frac{(\mathrm{X}-\mathrm{A}) \log \mathrm{Y}+(\mathrm{B}-\mathrm{X}) \log \mathrm{Z}}{\mathrm{B}-\mathrm{A}}
$$

where $\mathrm{X}=50 \%$ of the mean OD at $492 \mathrm{~nm}$ in 22 antigen control wells; $\mathrm{A}=$ mean $\mathrm{OD}$ values which are immediately lower than $X$ in the wells; $\mathrm{B}=$ mean OD values immediately higher than $\mathrm{X}$ in the wells; $\mathrm{Y}=$ the reciprocal of the serum test dilution at which $\mathrm{B}$ was determined; $\mathrm{Z}=$ the reciprocal of the serum test dilution at which $\mathrm{A}$ was determined, and $\mathrm{T}=$ antibody titers expressed as the logarithm of the reciprocal serum dilution. 
Figure 1 - Correlation and linear regression of antibody titers obtained by liquid phase blocking ELISA (LPB-ELISA) $\left(\log _{10}\right)$ and by serum neutralization test (SNT) $\left(\log _{2}\right)$. The equation for the line is: LPB $y=0.2322 x+$ $0.3419 ; r^{2}=0.892$

\section{Statistical analysis}

The correlation coefficient $\left(\mathrm{r}^{2}\right)$ between LPB-ELISA and SNT was determined for serological analysis (10). The cutoff point was determined by graphic analysis of the interception of the copositivity and conegativity curves of LPB-ELISA and SNT projected on the ordinate axis (11).

\section{Reproducibility of LPB-ELISA}

The reproducibility of the LPB-ELISA for antibody detection was determined using the OD values for serum dilutions of negative and positive controls, tested on twenty different days. These values were subjected

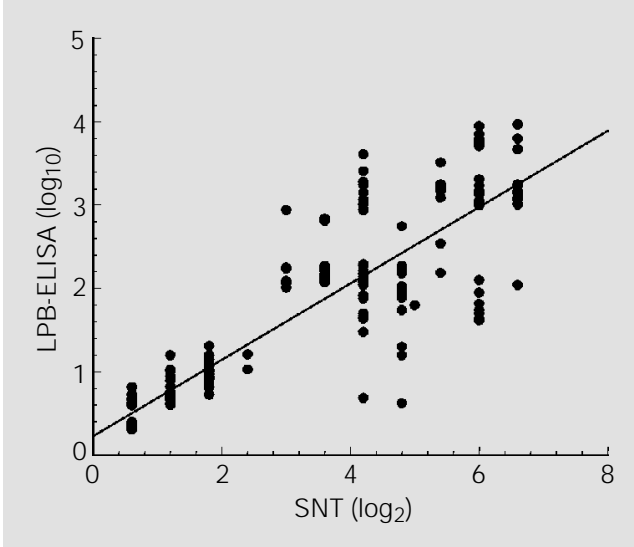

Table 1 - Specificity and sensitivity of LPB-ELISA for the determination of IBV-antibodies in vaccinated and nonvaccinated chickens.

aTotal number of serum samples from vaccinated chickens. bTotal number of serum samples from nonvaccinated SPF chickens. Specificity $=156-0 /$ $156 \times 100=100 \%$. Sensitivity $=100-12 / 100 \times$ $100=88 \%$. Agreement $=156+88 / 256 \times 100=$ $95.31 \%$.

\begin{tabular}{lcc} 
Serum neutralization test & \multicolumn{2}{c}{ LPB-ELISA } \\
\cline { 2 - 3 } & Positive & Negative \\
\hline Positive & 156 & 12 \\
Negative & 0 & 88 \\
Total number of serum & $156^{\mathrm{a}}$ & $100^{\mathrm{b}}$ \\
samples according to source & &
\end{tabular}

to statistical analysis by the Student $t$-test. The LPB-ELISA did not detect Newcastle disease, Reovirus or influenza A antibodies (data not shown). The results obtained are discussed below.

The chicken IBV-specific $\gamma$-globulin used as the capture antibody showed higher SN titer $\geq \log _{2} 8.0$. The trichloroacetic acid used for serum precipitation at $1 \%$ concentration eliminated the nonspecific reaction of the positive and negative avian serum components. In order to determine the best dilution for the capture antibody used to provide trapping, $\gamma$-globulin was titrated in a sandwich ELISA and the optimal dose was found to be $1: 250$ or $12.5 \mu \mathrm{g} /$ well.

The correlation coefficient between the LPB-ELISA and SNT for a total of 256 serum samples was $\mathrm{r}^{2}=0.8926(\mathrm{P}<0.0005)$ (Figure 1). The copositivity and conegativity results were determined with the cutoff being $\geq 0.6$. Table 1 shows the specificity $(100 \%)$ and sensitivity ( $88 \%)$ of LPB-ELISA for antibody detection. The agreement between LPB-ELISA and SNT was 95.3\%. The reproducibility of LPB-ELISA for antibody detection had a coefficient of variation of $2.4 \%$.

Antibody responses to the $\mathrm{S}_{1}, \mathrm{~S}_{2}, \mathrm{~N}$ and $M$ virus proteins were also detected in chicks vaccinated with the inactivated IBV strains. The $\mathrm{S}_{1}, \mathrm{~S}_{2}$ and $\mathrm{N}$ proteins all induced crossreactive antibodies which were detected by ELISA (1). In poultry, high specificity of serological tests is more important than high sensitivity, since low sensitivity can be compensated for by using a larger number of blood samples (4). The LPB-ELISA documented here demonstrated $100 \%$ specificity; however, when used at the cutoff level $\geq 0.6$ reported above, $95.3 \%$ agreement was found. In fact, the antigen reacts differently with its specific antibodies, depending on whether it is in the solid or liquid phase, as reported by McCullough et al. (10). With regard to the high agreement found here between the LPB-ELISA and SNT, we may 
speculate that the high levels of IBV-neutralizing antibodies were possibly detected by the liquid phase performed in the same way in the SNT $(4,9,11-13)$. The determination of $50 \%$ competitive antibody titers in LPBELISA by using the mathematical interpolation procedure on the basis of a larger number of antigen control wells than those described $(11,13)$ allowed a more precise estimate of these titers, considerably reducing the inter-test variation $(2.40 \%)$.

The use of chicken IBV-specific $\gamma$-globulin as capture antibody has several advantages over the use of rabbit polyclonal antiserum. Using the polyclonal antibody amplifies the nonspecific reactions with the allantoid fluid proteins, results also found in other studies $(6,7,14)$. In the present study, it was necessary to precipitate the chicken serum proteins, especially the IgM isotype, with $1 \%$ trichloroacetic acid to avoid nonspecific protein binding (15). This was confirmed by the results obtained for the positive and negative sera. In fact, it was the first time that LPB-ELISA was applied to chicken sera. This assay has not been used to measure anti-IBV antibodies in broiler chickens as frequently as the commercial indirect ELISA. In spite of the relatively higher correlation coefficients recorded for the indirect ELISA test, compared to the agar-precipitating gel test, HI test and SNT, it is important to emphasize the different intrinsic properties of each serological test (4).

The LPB-ELISA was compared here with the SNT, especially the liquid phase, where specific antibodies in the test sera effectively "block" the antigen and prevent it from reacting in the sandwich ELISA. Thus, the blocking ELISA developed here presented high specificity when compared with values reported by Esterhuysen et al. (9). The LPBELISA has been used to measure anti-footand-mouth and rabies virus antibodies in cattle and human sera, respectively $(9-11,13)$. Our results showed a significant correlation $\left(\mathrm{r}^{2}=0.8926\right)$ between the LPB-ELISA and SNT, similar to the results obtained in other studies $(10,11,13)$.

Certain types of ELISA, particularly "blocking" ELISA, may have a number of advantages over the serum neutralization test, but no serological test has indicated virus protection upon analysis. Therefore, the LPBELISA is considered a useful tool for routine laboratory diagnosis of IBV antibodies, thereby eliminating the need for cumbersome serological monitoring.

\section{Acknowledgments}

The authors wish to acknowledge the excellent technical assistance of Merial Laboratories in performing the hyperimmune sera.

\section{References}

1. Ignjatovic J \& Galli L (1995). Immune responses to structural proteins of avian infectious bronchitis virus. Avian Pathology, 24: 313-332.

2. Box PG, Holmes HC, Finney PM \& Froymann R (1988). Infectious bronchitis in laying hens: The relationship between haemagglutination inhibition antibody levels and resistance to experimental challenge. Avian Pathology, 17: 349-361.

3. Cavanagh D (1983). Coronavirus IBV glycopolypeptides: size of their polypeptide moieties and nature of their oligosaccharides. J ournal of General Virology, 64:
1187-1191.

4. Witt J J, Mekkes DR, Kouwenhoven B \& Verheijden J HM (1997). Sensitivity and specificity of serological tests for infectious bronchitis virus antibodies in broilers. Avian Pathology, 26: 105-118.

5. Cardoso TC, Montassier HJ , Galletti MCM \& Pinto AA (1996). Evaluation of indirect ELISA for monitoring antibodies against infectious bronchitis virus. Revista de $\mathrm{Mi}$ crobiologia, 27: 64-69.

6. Cardoso TC, Montassier HJ , Galletti MCM $\&$ Pinto AA (1996). Development and application of a sandwich ELISA to measure chicken antibodies to infectious bronchitis virus. Virus Reviews and Research, 1: 75-80.

7. Cardoso TC, Sousa RLM, Alessi AC, Montassier HJ \& Pinto AA (1998). A double antibody sandwich ELISA for rapid diagnosis of virus infections and to measure the humoral response against infectious bursal disease on clinical material. Avian Pathology, 27: 450-454.

8. Ann Hebert G, Pelham PL \& Pittman B (1973). Determination of the optimal ammonium sulfate concentration of fractionation of rabbit, sheep, horse and goat anti- 
sera. Applied Microbiology, 25: 26-36.

9. Esterhuysen JJ, Prehaud $C \& \&$ Thomson GR (1995). A liquid phase blocking ELISA for the detection of antibodies to rabies virus. J ournal of Virological Methods, 51 : 31-42.

10. McCullough $K C$, Bruckner $L$, Schaffiner $R$, Werner F, Heinz KM \& Ulrich K (1992). Relationship between the anti FMDV antibody reaction as measured by different assays and protection in vivo against challenge infection. Veterinary Microbiology, 30: 99-112.

11. Araujo JP, Montassier HJ \& Pinto AA (1996). Liquid phase blocking sandwich enzyme linked immunosorbent assay for the detection of antibodies against footand-mouth disease virus in water buffalo sera. American J ournal of Veterinary Research, 57: 840-843.

12. Cornaglia $\mathrm{E}$, Chretien N, Charara $\mathrm{S} \&$ Elazhary Y (1994). Detection of porcine respiratory coronavirus and transmissible gastroenteritis virus by an enzyme linked immunosorbent assay. Veterinary Microbiology, 42: 349-359.

13. Hamblin C, Barnett ITR \& Hedger RS (1986). A new enzyme linked immunosorbent assay (ELISA) for the detection of antibodies against foot-and-mouth dis- ease virus. I. Development and method of ELISA. J ournal of Immunological Methods, 93: 123-129.

14. Michalski WP, O'Rourke D \& Bagust TJ (1996). Chicken anaemia virus antibody ELISA: problems with non specific reactions. Avian Pathology, 25: 245-254.

15. De J onge N, Fillié YE \& Deelder AM (1987). A simple and rapid treatment (trichloroacetic acid precipitation) of serum samples to prevent non specific reactions in the immunoassay of proteoglycan. J ournal of Immunological Methods, 99: 195-197. 